\title{
Data Acquisition System for the Characterization of Biomechanical and Ergonomic Thresholds in Driving Vehicles
}

\author{
Juan F. Dols ${ }^{1, * \mathbb{D}}$, Vicent Girbés-Juan ${ }^{2} \mathbb{D}$, Álvaro Luna ${ }^{3}$ and Javier Catalán ${ }^{1}$ \\ 1 Institute for Design and Manufacturing (IDF), Universitat Politècnica de València, Camino de Vera, s/n. \\ 46022 Valencia, Spain; javiercatalanpechuan@gmail.com \\ 2 Departament d'Enginyeria Electrònica, Universitat de València, Av. Universitat, s/n. 46100 Burjassot, Spain; \\ vicent.girbes@uv.es \\ 3 Technical Service of Vehicle Reforms of Valencia (SETRAV), Polytechnic Innovation City (CPI), \\ Universitat Politècnica de València, Camino de Vera, s/n. 46022 Valencia, Spain; alvaro3luna@gmail.com \\ * Correspondence: jdols@mcm.upv.es; Tel.: +34-963877625
}

Received: 21 July 2020; Accepted: 25 August 2020; Published: 28 August 2020

check for updates

\begin{abstract}
Directive (EU) 2015/653 on driving licenses has involved the modification of different codes that must appear on driver's licenses. The definition of specific codes (20.07 and 40.01) compels measurement of the braking and steering forces. Performing practical tests to assess the driving fitness of special drivers will help to determine the maximum force that a driver can apply on primary controls when driving. From that point, definition of car control adaptations required to supply their functional deficiencies can be stated. This article describes a data acquisition system designed and developed for obtaining data from experimental tests based on the execution of habitual driving manoeuvres (braking, lane change and roundabouts). The data gathered will allow for definition of the thresholds of biomechanical values (forces on the steering wheel and brake pedal) and ergonomic values (driver's upper extremity mobility ranges) necessary for driving motor vehicles. The results have shown that application in real driving tests of the data acquisition system designed provides valid and suitable results for the case studied. Therefore, it will contribute to substantially improving the assessment procedure for drivers in general and for disabled people in particular when obtaining or renewing their driving licenses.
\end{abstract}

Keywords: biomechanical thresholds; car control adaptations; data acquisition system; driving ergonomics; driving fitness; motion capture

\section{Introduction}

The lack of accessibility to transportation systems is still one of the most limiting disadvantages that people with disabilities must overcome to seek work or receive health care [1]. In the European Union (EU), it was estimated that, in 2012, there were about 70 million people over 15 years old with some kind of disability, which represented $17.6 \%$ of its population [2]. According to projections, this value will increase to 120 million in 2020, considering population aging [3].

The reference directive for obtaining a driving license is currently 2006/126/EC of the European Parliament and of the council [4]. Article 7 of this directive stipulates that the driving license must be issued only to people who have passed the fitness-to-drive, driving ability and behaviour tests and who also meet medical standards in accordance with annex II-devoted to establishing criteria on the knowledge, skills and behaviours required to drive a motor vehicle—and annex III—which indicates the minimum health requirements to drive. Annex I of this directive lists codes and subcodes that 
must be included in the driving license. These codes clearly establish the definition of limitations in driving or adaptations to the vehicle to be driven by a disabled driver.

Directive (EU) 2015/653 of the commission [5] was published to amend Directive 2006/126/EC, upgrading the codes and subcodes established in annex I of Directive 2006/126/EC to the current state-of-the-art, both concerning technological developments in the automotive sector as well as further adaptations and technical aids. Some of the modifications introduced in this new directive consider assessment of the maximum force that can be applied by a driver on the primary controls (steering devices and brake pedal). Furthermore, the required technical adaptations are determined in order to fulfil whatever disability the driver may present [6].

Due to the lack of information about current thresholds values for the force required to drive vehicles, it is necessary to develop a methodology that evaluates and studies these requirements as well as a data acquisition system (DAS) to log data while driving. Therefore, the main goal of the present study is to design and develop a DAS to measure and log the forces-torques—and movements that a driver performs when executing representative manoeuvres (changing direction in the left and right corners, as a slalom, roundabout or braking manoeuvres) while driving a vehicle.

The DAS developed in this research was based on the technical requirements stablished by Luna (2018) [7] in a previous work, which establishes the conditions that must be fulfilled:

- Reliable: the range of values to be measured with the DAS must be within the valid measuring range of the system as well as must have a sampling frequency suitable for the parameter to be measured.

- Robust: the DAS must be able to optimize the time spent in the realization of tests, so the system must not present problems that slow down or make its correct setup more complex.

- Portable: because its intended use is for motor vehicles, requiring quick assembly, the DAS must be easily and quickly portable.

Because the environment in which the DAS has been developed belongs to the Technical Service for Vehicle Inspections of Valencia (SETRAV) and the Institute for Design and Manufacturing (IDF) of the Universitat Politècnica de València (Spain), regulation UNE-EN ISO/IEC 17025:2017 [8] was applied in this project. This standard is applied in testing and calibration laboratories in order to demonstrate that they are technically competent and that their results are true. The standard specifies the environmental conditions of the laboratories and calibration methods as well as the validation of these methods. Basic rules for the use of equipment are established, and guidelines are given for sampling, traceability of measurements, and handling of test or calibration items.

Therefore, the DAS developed should be compliant with the quality described in these regulations. The approach followed within this project aims towards the future development of a database, built from the results obtained in the experimental tests. In this way, the efforts and movements of people with reduced mobility could be evaluated individually to determine their aptitude to obtain a driving license. The results obtained will conclude that the DAS developed provides valid, reliable and suitable results for the case studied.

\section{Materials and Methods}

\subsection{Sensors}

Considering the requirements of Directive (EU) 2015/653 [5] and the testing scenarios, the sensors included in the DAS are as follows:

- a brake pedal load cell and, additionally, a throttle pedal load cell;

- a steering wheel torque sensor;

- $\quad$ an Inertial Measurement Unit (IMU) with Global Positioning System (GPS); and

- a set of 8 human motion trackers. 
Figure 1 shows the proposed data acquisition architecture, which combines a motion tracking system for the driver's position, GPS + IMU data for measuring vehicle dynamics, as well as force and torque sensors attached to the pedals (brake and throttle) and the steering wheel. Two signal amplifiers (model AD620) are required to scale up the signals measured from the load cells and torque sensor. Two Arduino UNO were also included to read the sensor signals and to send them to the computer used as data logger.

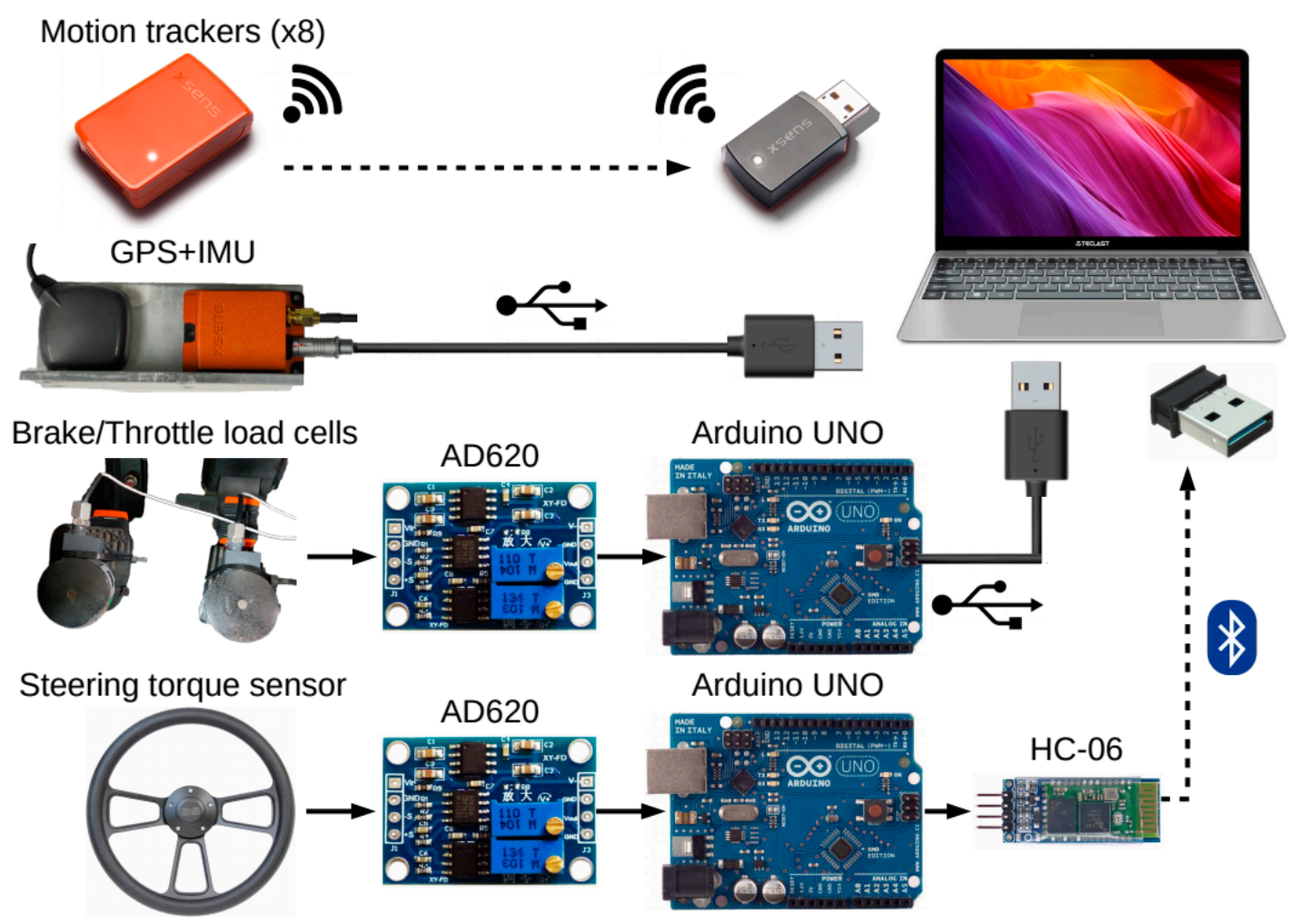

Figure 1. Data acquisition architecture.

Starting with the torque sensor of the steering wheel, the model used was Mecmesin ST60, with a full scale of $\pm 60 \mathrm{Nm}$ and a resolution of $0.02 \mathrm{Nm}$, making it suitable for the current application. The design of the attachment requires installation of an adaptor for the original steering wheel, as showed in Figure 2. The design uses a worm screw system to make it adaptable to a wide range of steering wheel sizes for different vehicles [9]. Inside the assembly, an Arduino UNO board with Bluetooth HC-06 wireless transceiver has been included to send data to the computer at a rate of $100 \mathrm{~Hz}$. Three $5 \mathrm{~V}$ batteries are attached to the centre of the steering wheel to supply power to the Arduino board $(+5 \mathrm{~V})$ as well as positive and negative reference voltages $( \pm 5 \mathrm{~V})$ to the amplifier AD620.

The brake pedal and throttle pedal force sensors correspond to Honeywell 3663-200 load cells with a full scale of $890 \mathrm{~N}$ (200 pounds). This sensor works with the principle of a strain gauge with a Wheatstone bridge, so a differential operational amplifier can be used to accurately measure the applied force. Both load cell sensors are attached directly to the brake and throttle pedals and wired to the amplifiers AD620, for which the output is connected to two analogue inputs of the Arduino UNO board. The microcontroller sends information (sampled at $100 \mathrm{~Hz}$ ) to the computer using a serial protocol through a USB port connection.

Regarding the IMU used for measuring vehicle dynamics, the model selected was the Xsens MTi-G710 GNSS, already used in previous work done by the authors [10]. The IMU incorporates the following components: three-axis magnetometer (full range \pm 8 Gauss, Root Mean Square (RMS) noise $0.5 \mathrm{mG}$ ), three-axis gyroscope (full range $\pm 7.85 \mathrm{rad} / \mathrm{s}$, bias error $0.0035 \mathrm{rad} / \mathrm{s}$ ), three-axis accelerometer (full range $\pm 200 \mathrm{~m} / \mathrm{s}^{2}$, bias error $0.05 \mathrm{~m} / \mathrm{s}^{2}$ ) and a barometer (full range 30-110 kPa, RMS noise 3.6 Pa). The dynamic 
accuracy of the orientation is $0.005 \mathrm{rad}$ (pitch/roll) and $0.014 \mathrm{rad}$ (yaw). Regarding the GPS, the horizontal accuracy is $1 \mathrm{~m}$ (Cartesian coordinates $\mathrm{x} / \mathrm{y}$ ), and the vertical accuracy is $2 \mathrm{~m}$ ( $\mathrm{z}$ coordinate).

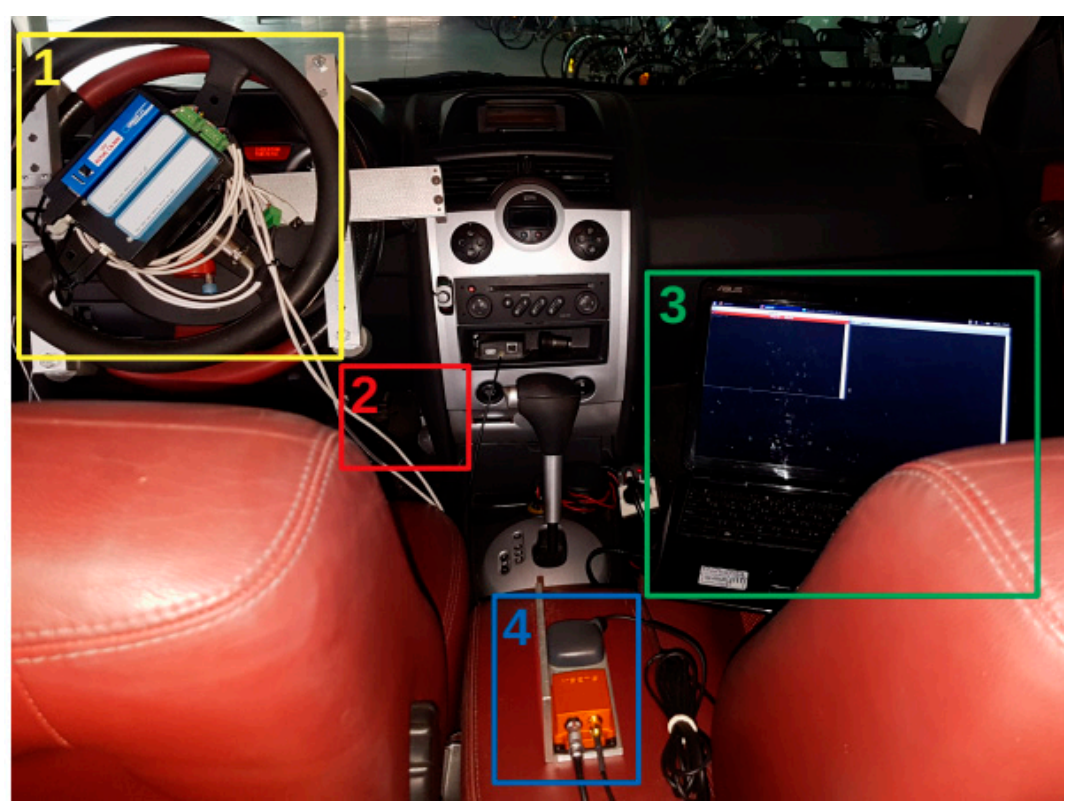

Figure 2. Overall layout of the system: 1. steering wheel torque sensor; 2. pedal load cell; 3. computer; and 4. inertial measurement unit and Global Positioning System (GPS) receiver.

This electronic device implements internally an Extended Kalman Filter for sensor data fusion, combining information from different sources (accelerometer, gyroscope, magnetometer, altimeter, etc.) and increasing the accuracy and robustness of the estimation. The GPS + IMU device will be used to measure position, velocity and acceleration, logging data at a sampling rate of $100 \mathrm{~Hz}$. It is important to highlight that it fulfils the IP67 regulation, so it provides additional robustness to the system. Additionally, it has a 9-pin mini DIN (Deutsches Institut für Normung) port, so it is directly connected by USB to the computer. The GPS + IMU device must be mounted in the vehicle's centre of mass or in the nearest possible position and can be fixed by using double sided tape or any other reliable fixation method. It is important to follow the product user's guide to determine the correct orientation of the device with respect to the XYZ axis of the vehicle, as showed in Figure 3. In this case, a positive $\mathrm{X}$ was the forward positive direction of the vehicle.

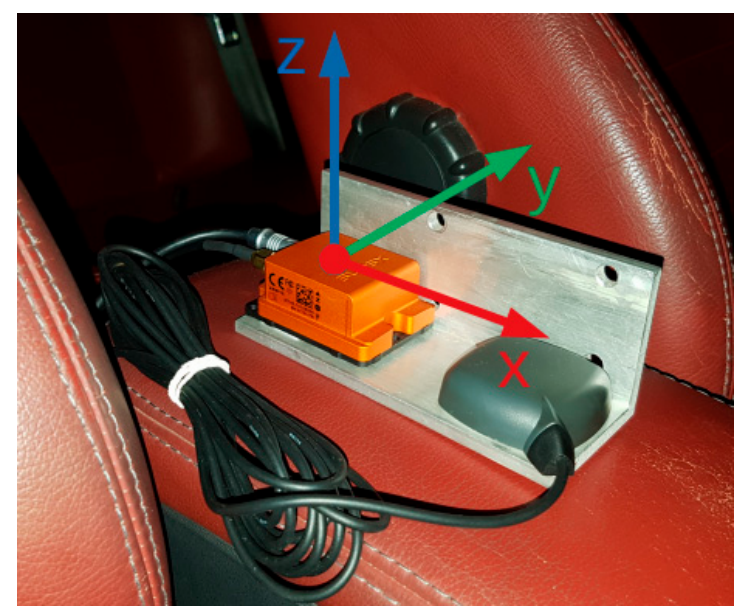

Figure 3. Position and orientation of the inertial measurement unit. 
The human motion trackers are IMUs with $9 \mathrm{DoF}$ (Degrees of Freedom), combining the information of three-axis gyroscope (full scale $\pm 34.9 \mathrm{rad} / \mathrm{s}$ ), three-axis accelerometer (full scale $\pm 160 \mathrm{~m} / \mathrm{s}^{2}$ ) and three-axis magnetometer (full scale \pm 1.9 Gauss). They have an internal sampling rate of $1 \mathrm{kHz}$ and a highly accurate time-synchronized data sampling, lower than $10 \mu \mathrm{s}$. The dynamic accuracy for roll and pitch angles is 0.013 rad RMS, whilst for yaw angle or heading, it is 0.026 rad RMS. Their lightweight design of only 16 grams per device makes them suitable for use without influencing the driver's comfort. They communicate with the computer by a $2.4-\mathrm{GHz}$ radio frequency (RF) connection, having battery autonomy of 6 hours. The acquisition sampling rate was set to $100 \mathrm{~Hz}$, that is suitable for the kind of measurements performed, although it could be set up to $120 \mathrm{~Hz}$, based on the manufacturer's specifications.

As specified before, a set of 8 human motion trackers was used to log the movements of the driver. Distribution of motion trackers on the driver is showed in Figure 4. In order to achieve a good model of the human body, it is advisable to fit the motion tracker while in a resting position, the three devices of the arm creating a vertical line, as represented in Figure 4. Each motion tracker is associated with an upper body element, with $\mathrm{A}, \mathrm{F}$ and $\mathrm{H}$ being the arm, forearm and hand, respectively; where $\mathrm{L}$ refers to left side and $\mathrm{R}$ refers to right side. The head $(\mathrm{H})$ and back/body $(\mathrm{B})$ are also tracked by the motion capture system.

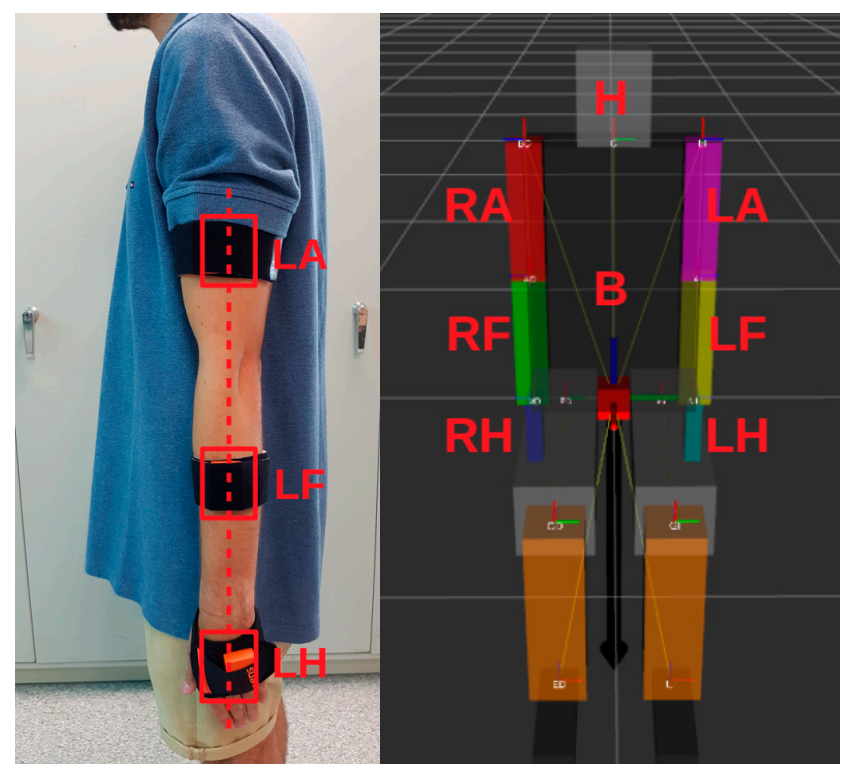

Figure 4. Distribution of human motion trackers.

Finally, a computer is used to log all data by making use of software that will be explained later as well as the minimum operational requirements. This computer must be connected during the whole testing session. Just in case the autonomy of the computer runs out, it could be plugged into the vehicle's $12 \mathrm{~V}$ output or it can include a $12 \mathrm{~V}$ battery, using a power inverter in both cases. This would be the only device that would depend on the car's electrical system, since the rest of the sensors are powered by independent batteries.

\subsection{Software}

To develop the data acquisition system, a careful process on software benchmarking was followed considering the features, possibilities and license limitations. Finally, the following software was selected:

- Xubuntu 16.04: based on Linux, it provides better efficiency with lower system requirements. Despite that, the advisable minimum requirements are space disk of at least 7.5 GB and $512 \mathrm{MB}$ of Random Access Memory (RAM); 
- Robot Operating System (ROS): a flexible opensource framework, mainly developed for robot software using $\mathrm{C}++$ and Python. In this case, RVIZ (ROS visualization) is a 3D visualization tool for ROS required to represent the 3D model of the driver;

- Terminator: an opensource tool for arranging terminals that will be used to work with the ROS terminals in a grid screen layout;

- MATLAB: a numerical computing environment developed by MathWorks, that will serve as a data analysis tool. Notice that OCTAVE could also be used, which is a free opensource version; and

- Additional drivers: required by each one of the sensors to work properly and to be able to connect, send and receive data to the computer.

\subsection{Sensor Calibration}

To fulfil the UNE-EN ISO/IEC 17025:2017 regulations [8], a process for sensor calibration has been developed and followed before each testing. Both steering wheel and pedal load cell sensors were calibrated using Mecmesin Compact Force Gauge+ $(\mathrm{CFG}+)$ developed to be used in compression or traction tests with a full scale of $500 \mathrm{~N}$.

During the calibration process of the steering wheel's torque sensor, the CFG+ must be parallel to the steering wheel front surface. To do so, the gauge must be attached tightly at the application point of the steering wheel, where the force must be applied perpendicular to the steering wheel's radii. It is important to measure accurately the radius of the application point (which is not necessarily the outer radius). In order to obtain the torque applied at the centre of the steering wheel, the equation $T=F \cdot R$ was applied, where $\mathrm{T}$ is the resulting torque, $\mathrm{F}$ is the applied force and $\mathrm{R}$ is the radius or distance from the force application point to the centre of the steering wheel. It is recommended to perform the calibration both in the clockwise and counterclockwise directions to ensure that the sensor is working correctly in both directions. During this process, it is advised to take at least 20 measurements for each direction, starting at $10 \mathrm{~N}$ and finishing at $160 \mathrm{~N}$, where the CFG+ measure as well as the value obtained from the sensor must be written. After, multiply the CFG+ value by the application point radius to obtain the torque applied. Figure 5 shows the measured torque of the steering torque sensor (clockwise) versus the digital value of a 10-bit Analog-to-Digital Converter (ADC). From here, it is possible to calculate a linear regression and to check that the $\mathrm{R}^{2}$ value is as close as possible to 1 ; see Figure 5 for details.

The same methodology must be followed to calibrate each pedal's load cell (brake and throttle). In this case, the force must be applied perpendicularly to the cell surface, so that it is aligned to the measurement gauge. Figure 6 shows the calibration of the brake's load cell, with the throttle's load cell values being very similar. It can be clearly observed that the data is linear, so the regression can be fitted to a straight line.

For estimation of the driver's upper body posture, 8 motion trackers are used in the proposed DAS, as explained in Section 2.1. For each driver, we measured arm length (from shoulder to elbow), forearm length (from elbow to wrist), hand length (from wrist to fingertip), back height (from hips to shoulders), back width (distance between outer shoulders) and head height including the neck. Then, a kinematic model of the upper body of the human was created using these measurements, implementing two open kinematic chains, one for each arm. The motion trackers measurements were very accurate for the linear acceleration, angular velocity, roll and pitch angles, but due to magnetic interference, the heading (magnetic North reference) of the motion trackers could be biased so a reset was required in order to align the yaw angles of all the devices. This reset must be done before the driver gets in the vehicle in a repose standing position. After the calibration is done, a real driver and the human model can be visually compared using RVIZ to check the correlation between them. In case they are not synchronized, a reset must be done again before the driving test is performed. 


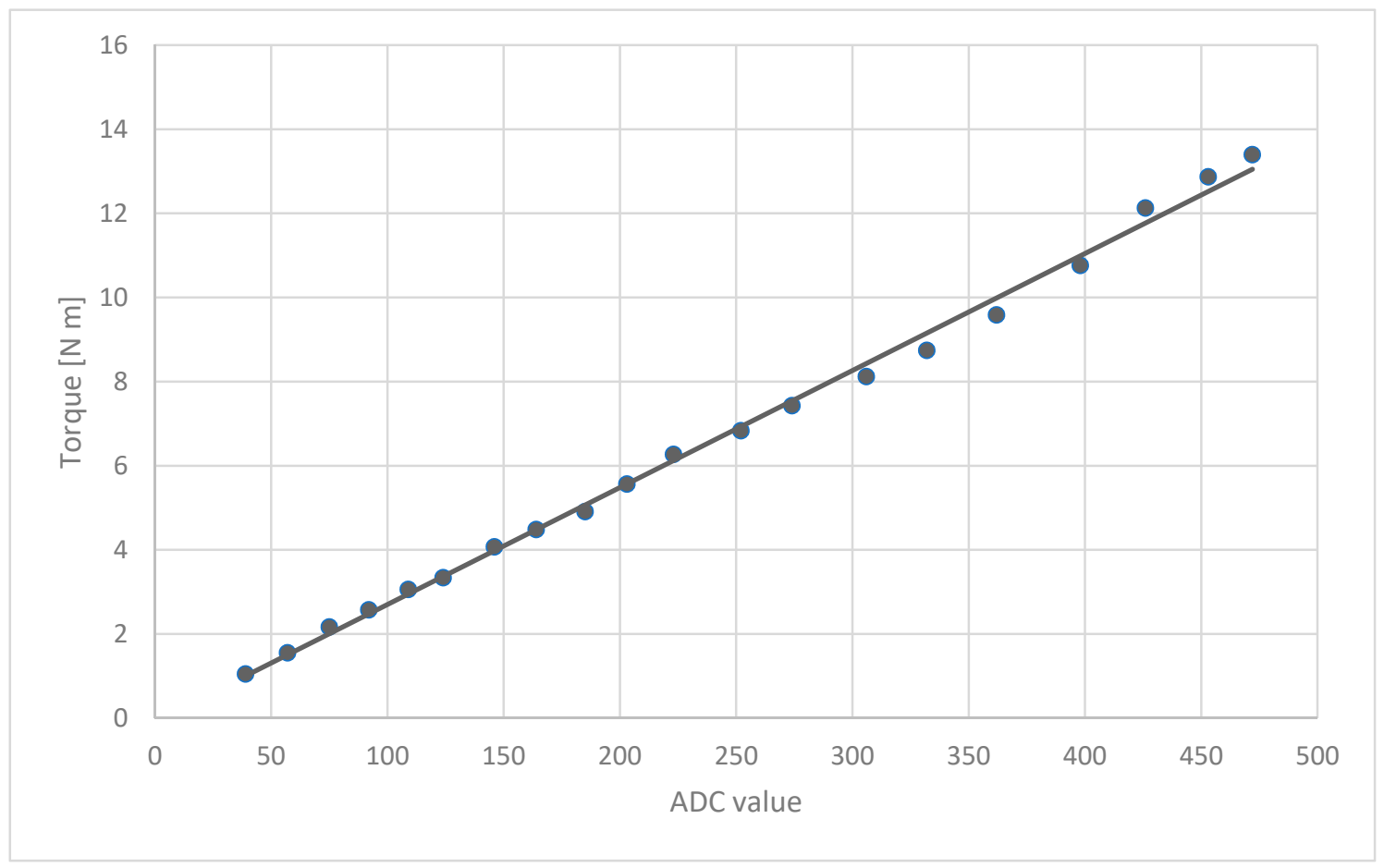

Figure 5. Steering wheel's torque sensor calibration from Analog-to-Digital Converter (ADC) converter values.

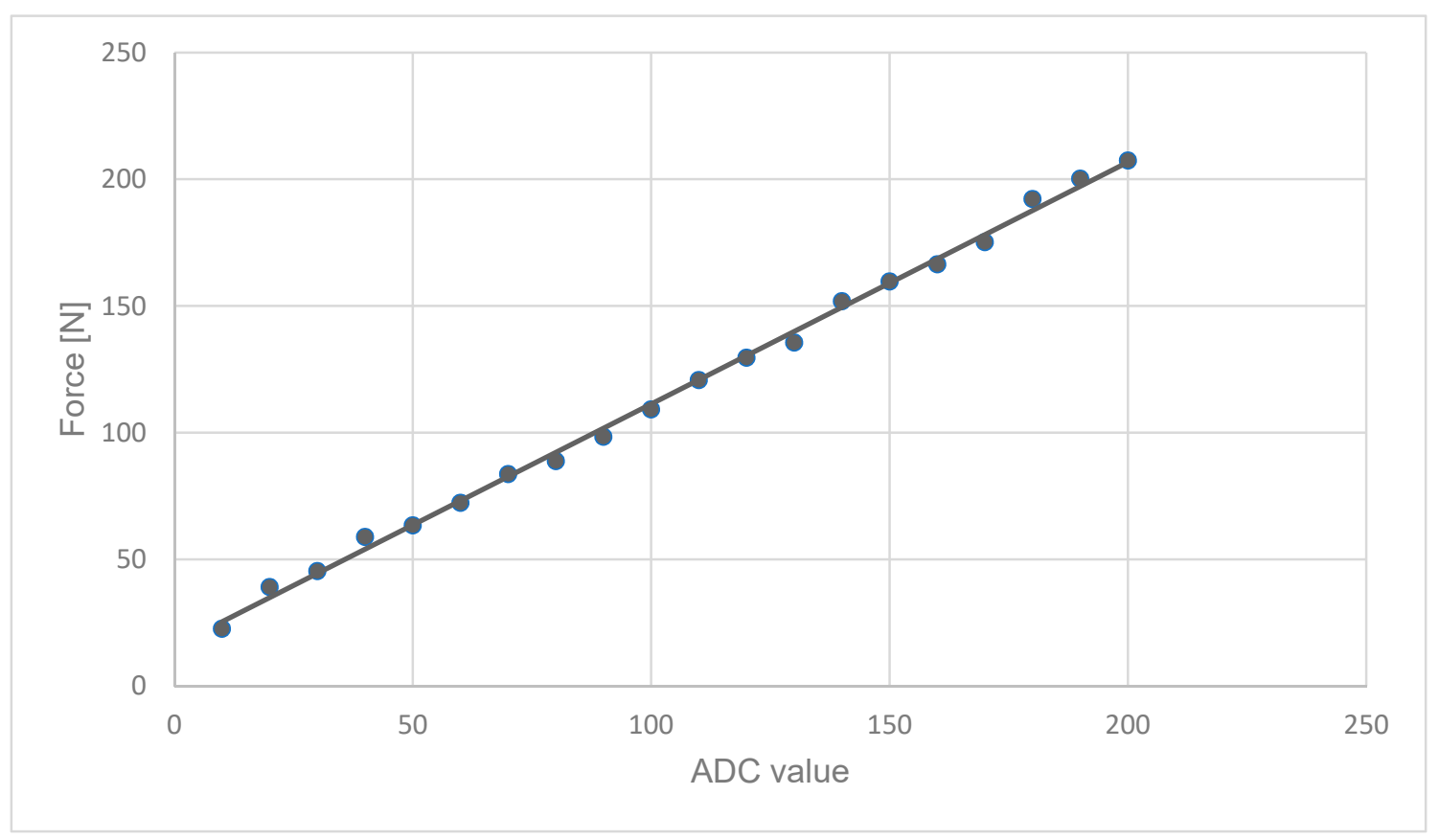

Figure 6. Brake's load cell calibration from ADC converter values.

\subsection{Track Testing}

Three different drivers that have been owners of a driving license for at least 2 years and with ages between 24 and 56 years performed track testing to check and validate proper functioning of the system. A total of four different scenarios were developed to test the system (showed in Figure 7):

- Braking: driving at a constant speed of $50 \mathrm{~km} / \mathrm{h}$, the driver will push the brake pedal when crossing a reference line in order to brake the car and to stop it. 
- Slalom: driving around corners and changing direction lanes (left and right turns) and with 5 cones in a straight line at $15 \mathrm{~m}$ between them, the driver will have to drive between them, doing a zig-zag manoeuvre at a speed of $30-35 \mathrm{~km} / \mathrm{h}$.

- Roundabout 1: following a circular path of 10 meters of radius, the driver must keep a speed of $30-35 \mathrm{~km} / \mathrm{h}$ in a clockwise direction.

- Roundabout 2: the same manoeuvre as roundabout 1 is performed but in the counterclockwise direction.
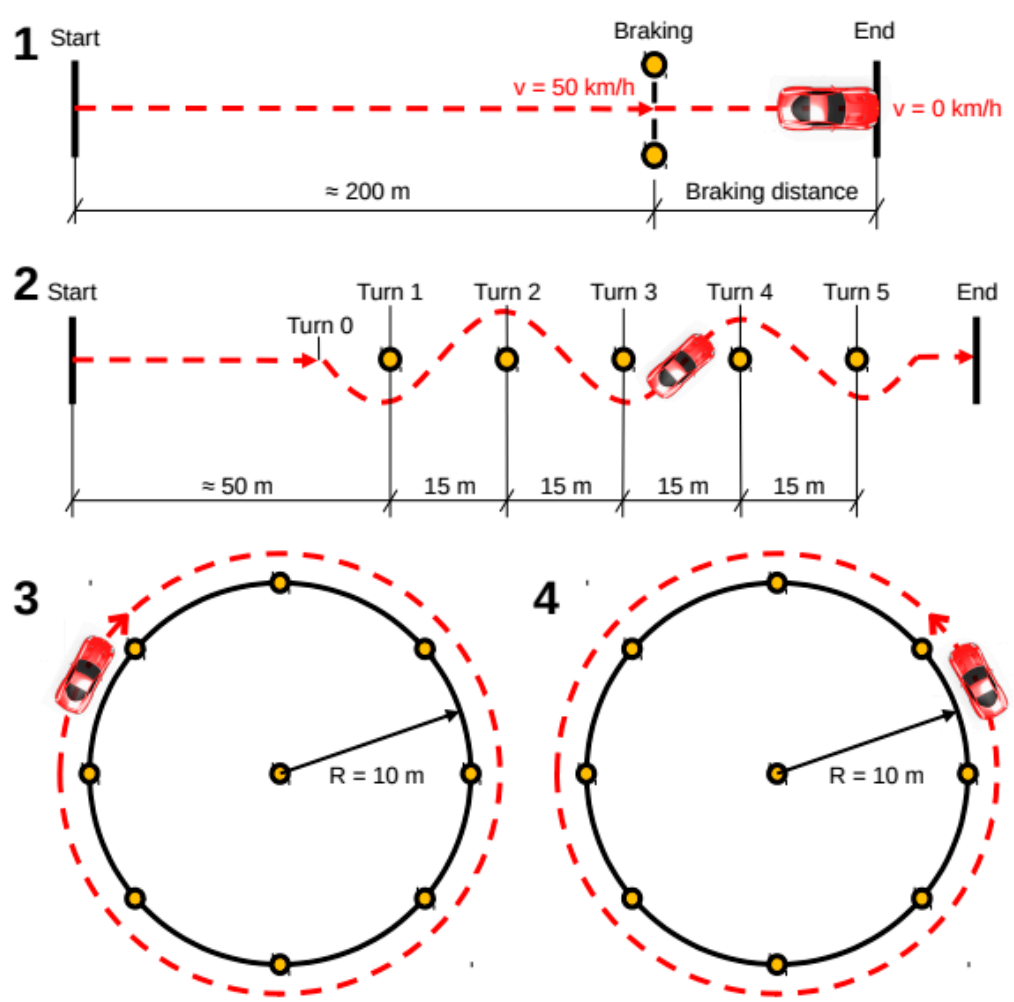

Figure 7. Testing scenarios: 1 . braking; 2. slalom; 3 . roundabout 1 ; and 4 . roundabout 2.

For validation of the system, two different vehicles were used. The features of each one of them are showed in Table 1. Features like anti-lock braking system (ABS) and power steering are important in order to correctly understand the results that will later be explained. Every driver did each one of the testing scenarios with each car, so that a total of 24 rounds of data were achieved. After each round, a quick visualization of the data was performed in order to check possible issues. Furthermore, after every single test, a template test sheet was filled out with fundamental information such as time of day, driver's name, vehicle and the testing scenario. It is important that, before starting any test, the driver must feel comfortable, checking that none of the sensors are disturbing drivability of the vehicle. Furthermore, the data acquisition system must be working and logging data correctly. Lastly, the weather during the test must be in favourable conditions (no adverse weather conditions).

The DAS implemented was aimed to be a robust, reliable and portable tool that allows for obtainment of the ranges of mobility of the driver's upper extremities as well as the forces applied at the steering wheel and at the brake pedal. As shown in Table 1, the main difference between the technical characteristics of the testing vehicles was based on the type of transmission. A vehicle with a manual gearbox and another with an automatic transmission were used, so that, during the validation tests, the maximum range of movements of the driver's upper extremities could be compared during the performance of the defined driving manoeuvres. 
Table 1. Features of the vehicles tested.

\begin{tabular}{ccc}
\hline Vehicle's Data Sheet & Vehicle 1 & Vehicle 2 \\
\hline Manufacturer & Renault & Ford \\
\hline Model & Clio & Focus \\
\hline Year & 2014 & 2010 \\
\hline Fuel & Petrol & Diesel \\
\hline Transmission & Automatic & Manual \\
\hline Engine $(\mathrm{cc})$ & 1197 & 1560 \\
\hline ABS & Yes & Yes \\
\hline Power steering & Yes & Yes \\
\hline Vehicle gross weight $(\mathrm{kg})$ & 1165 & 1277 \\
\hline Power $(\mathrm{kW})$ & 88 & 66 \\
\hline
\end{tabular}

\section{Results}

After carrying out the track tests to verify the correct functioning of the sensors and the DAS, we obtained the data. In this section, the data will be displayed and analysed for the verification and validation of the most relevant tests. For validation of the steering wheel torque meter and the brake pedal load cell, the plots that represent the effort applied on the steering wheel and the brake pedal have been obtained.

\subsection{Steering Testing}

\subsubsection{Slalom Testing}

In Figure 8, the steering torque results of the slalom tests (2 per driver, 6 in total) are shown. As can be seen, all tests show the same overall values, with peak values of $4 \mathrm{Nm}$ clockwise and counterclockwise, that represents a force of $24.2 \mathrm{~N}$ on the steering wheel periphery, taking into account a steering wheel diameter of $0.165 \mathrm{~m}$. The data plotted for different drivers and vehicles presents overall similar maximum and minimum values. It is important to remember that, as noted in Table 1 , both vehicles have power steering.

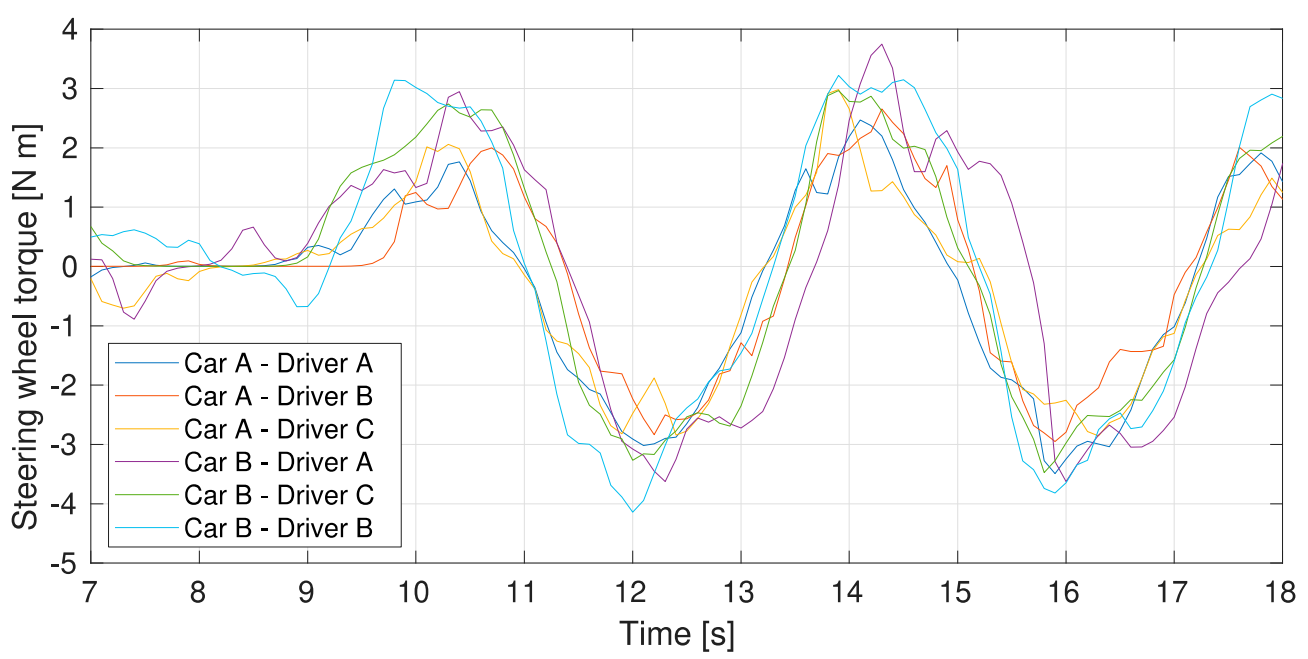

Figure 8. Steering wheel torque results in slalom tests. 


\subsubsection{Roundabout Testing}

Figure 9 shows the plots obtained for the torque measured on the steering wheel during the 12 roundabout circulation tests carried out, 6 of them clockwise and the remaining 6 counterclockwise. Regardless of the direction of rotation, it can be seen in both images that the torque margin obtained at the steering wheel periphery varies between a value from 2 to $4 \mathrm{~N} \mathrm{~m}$, obtained during a steady-state vehicle speed of $30 \mathrm{~km} / \mathrm{h}$ along a period of $30 \mathrm{~s}$. This torque represents, taking into account the distance of $0.165 \mathrm{~m}$ between the point of application of force on the steering wheel and the centre of rotation, a force of $12.12 \mathrm{~N}$ to $24.24 \mathrm{~N}$.

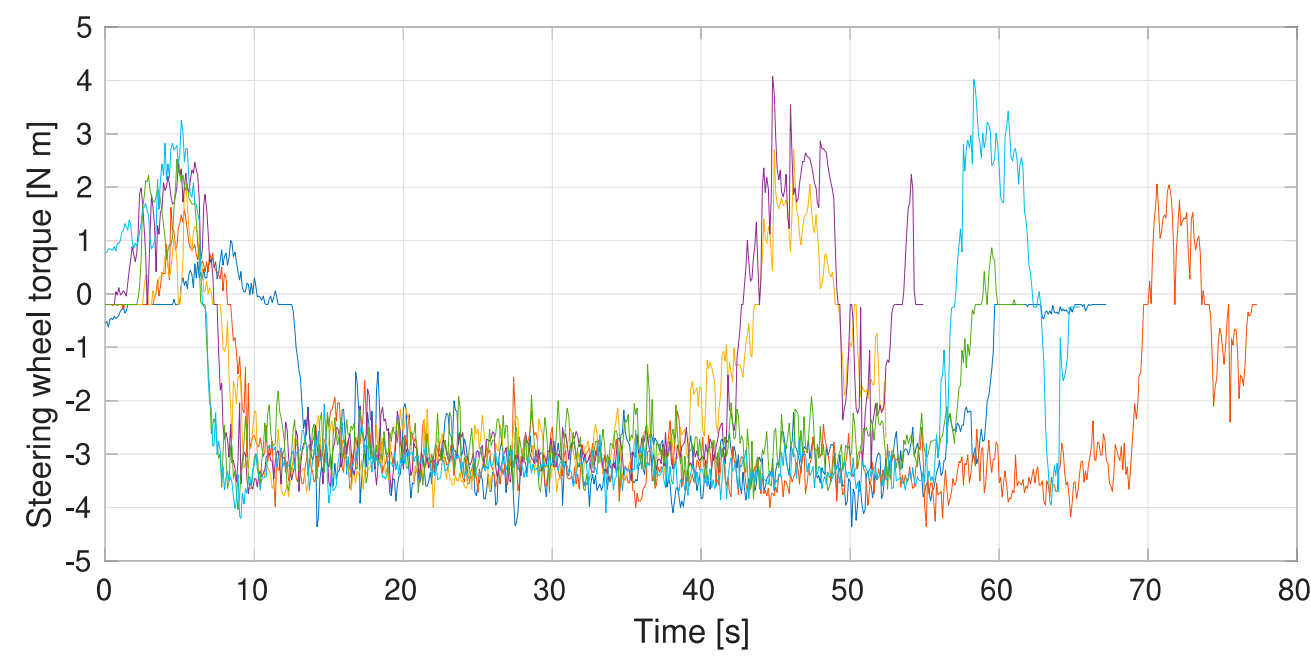

(a)

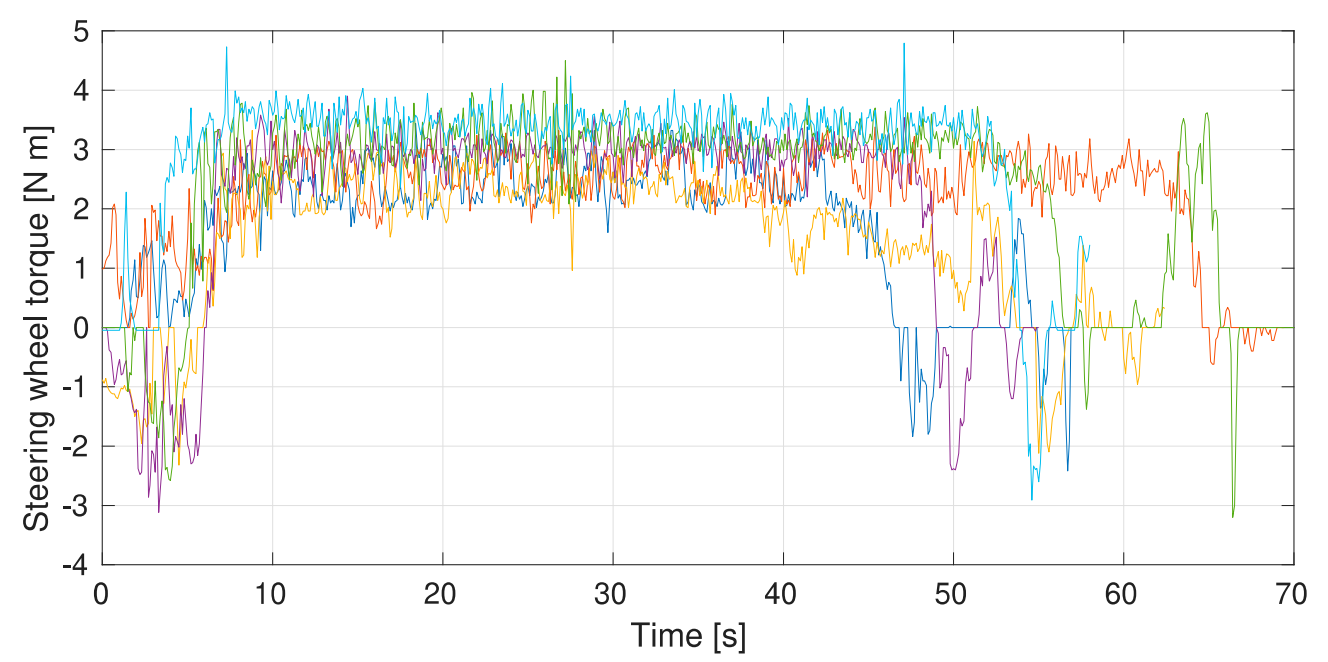

(b)

Figure 9. Steering wheel torque results in roundabout tests: (a) clockwise direction and (b) counterclockwise direction.

In general, considering the tests performed to measure the maximum force on the steering wheel for both testing vehicles and different types of drivers, the results provided a similar value for the driving tests that represent a lane change (slalom) and driving in traffic roundabouts. These maximum values were defined around $24.2 \mathrm{~N}$.

The starting, average and finishing speeds were analysed for all tests in order to check that the values were acceptable for all scenarios, although all these results are not shown for brevity. 
Furthermore, the trajectory of the designed scenarios and the position received by the GPS sensor were compared to verify their similarities, as showed in Figure 10a.

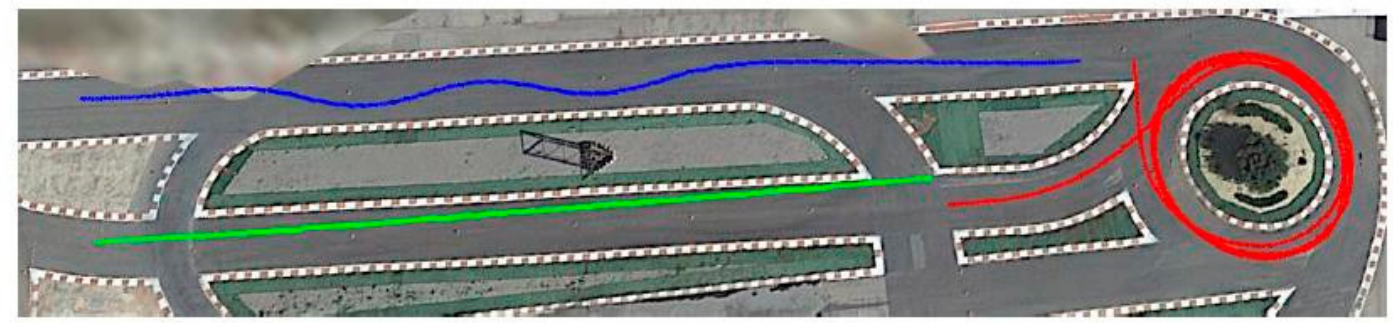

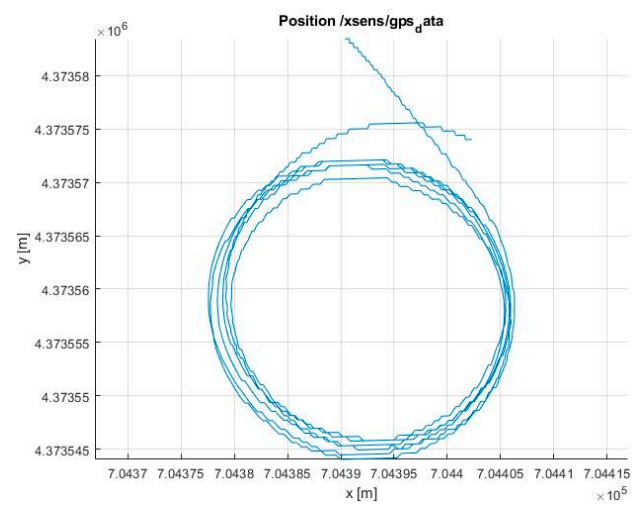

(b) (a)

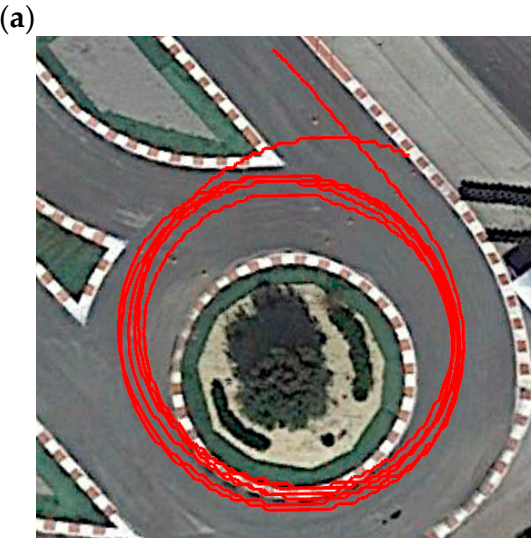

(c)

Figure 10. GPS sensor data of the scenarios: (a) scheme of the different driving test scheduled, with blue representing slalom, green representing braking and red representing roundabouts; (b) trajectory obtained during the roundabout test using the Inertial Measurement Unit (IMU) sensor; and (c) trajectory obtained during the roundabout test from a GPS sensor.

For example, the results of the roundabout test can be observed in Figure 10b,c. This circulation test consisted of making a trajectory turning around a roundabout for one minute, trying to maintain a constant speed of $30 \mathrm{~km} / \mathrm{h}$. Figure 10b shows the data recorded by the inertial sensor, and Figure 10c shows the result of the trajectory obtained from the measurement with the GPS. In both cases, the trajectories coincide with great accuracy as well as the values of the speed obtained, since in all tests, the speed indicated by the vehicle's speedometer coincided with the speed recorded by the inertial measurement unit.

\subsection{Braking Testing}

Regarding the braking scenario, the maximum measured force has an average value of $137.5 \mathrm{~N}$ and the minimum peak force has an average value of $85.6 \mathrm{~N}$, as showed in Figure 11. As well as in the previous scenario, the data follows a common pattern, except the purple line, where the driver was not able to brake correctly at first instance and kept the brake pedal pushed.

Figure 12 shows a representation of the results obtained for linear vehicle speed during the braking test. In this figure, it can be seen that, in all tests, the drivers brake suddenly when the linear speed has a value between 49 to $53 \mathrm{~km} / \mathrm{h}$. The purple line is offset in time due to the codriver in that test starting the DAS ahead of time. It can also be appreciated in the light blue, green and purple lines that the initial increasing slope (when the vehicle is accelerating) presents a series of steps. This is due to the fact that these tests were carried out with vehicle 2 that has a manual transmission, so these small speed losses are caused by gearbox changes. On the other tests, carried out with vehicle 1 with automatic transmission, this does not happen in a notable way. Finally, a similar tendency in braking behaviour and maximum speeds for all the tests can be observed. 


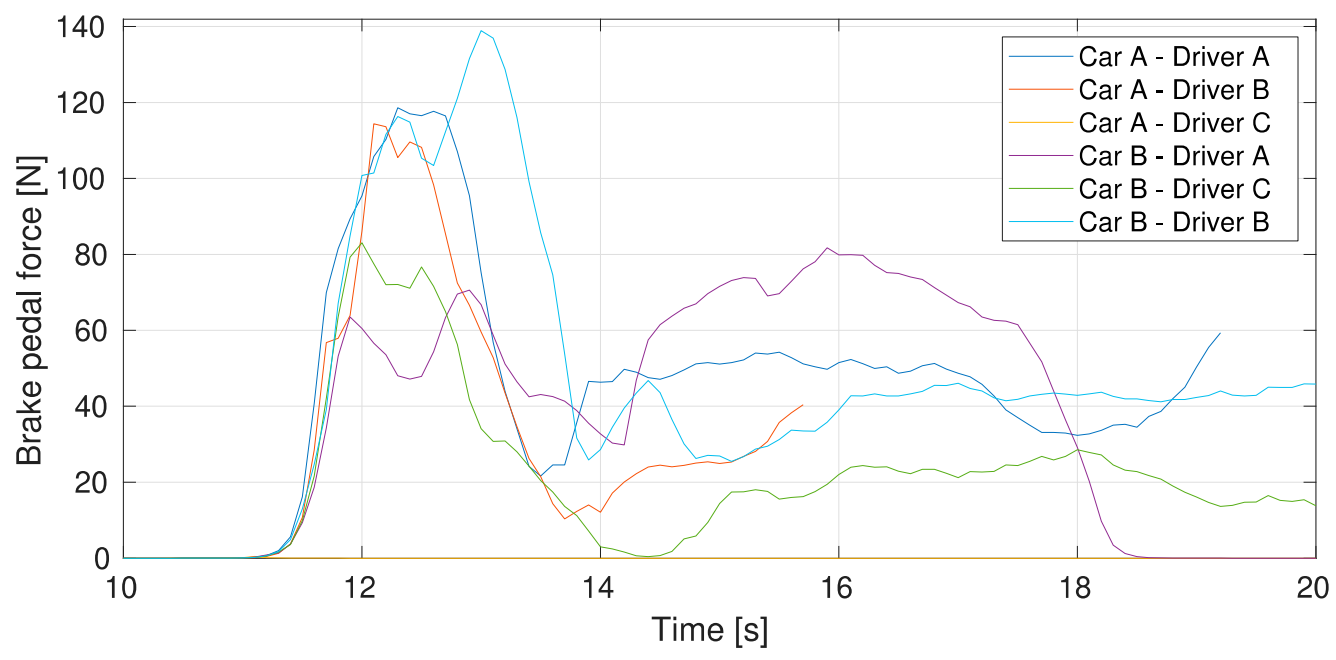

Figure 11. Brake pedal load cell results in braking tests.

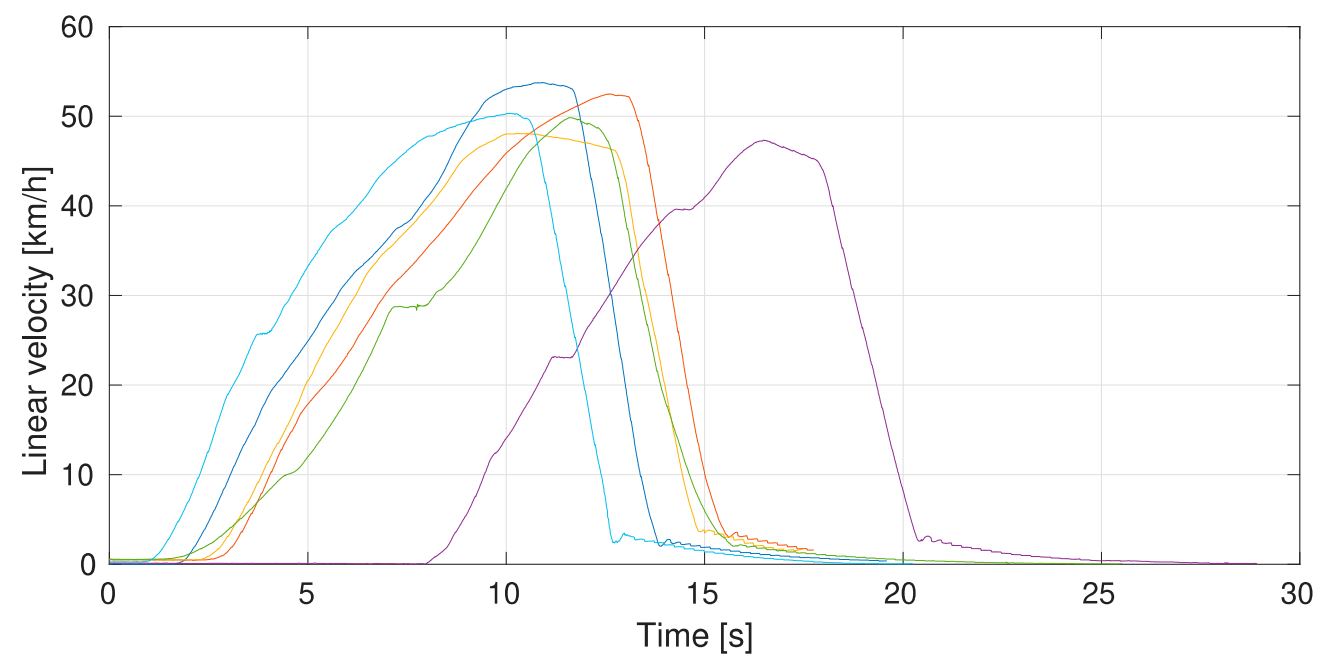

Figure 12. Linear velocity results in braking tests.

\subsection{Driver Model Testing}

A visual comparison of the 3D driver model is showed in Figure 13, which represents a real manoeuvre done by the driver to check correct functioning of the human motion tracker. To obtain a 3D model representing the behaviour of the upper extremities of the driver during the performance of the established driving manoeuvres, the 8 motion trackers previously described were used. Each of these sensors recorded data on the position, speed and acceleration in the $\mathrm{X}, \mathrm{Y}$ and $\mathrm{Z}$ directions. Analysis of the signals recorded for each one of the sensors in each one of the directions allowed for reproduction of the behaviour of the driver during its execution in each type of driving test. Analysis of the different movements could later be analysed in the laboratory to determine the maximum ranges of each of the upper extremities during the execution of the driving manoeuvres as well as the speeds and accelerations suffered by the driver's trunk and upper extremities. 


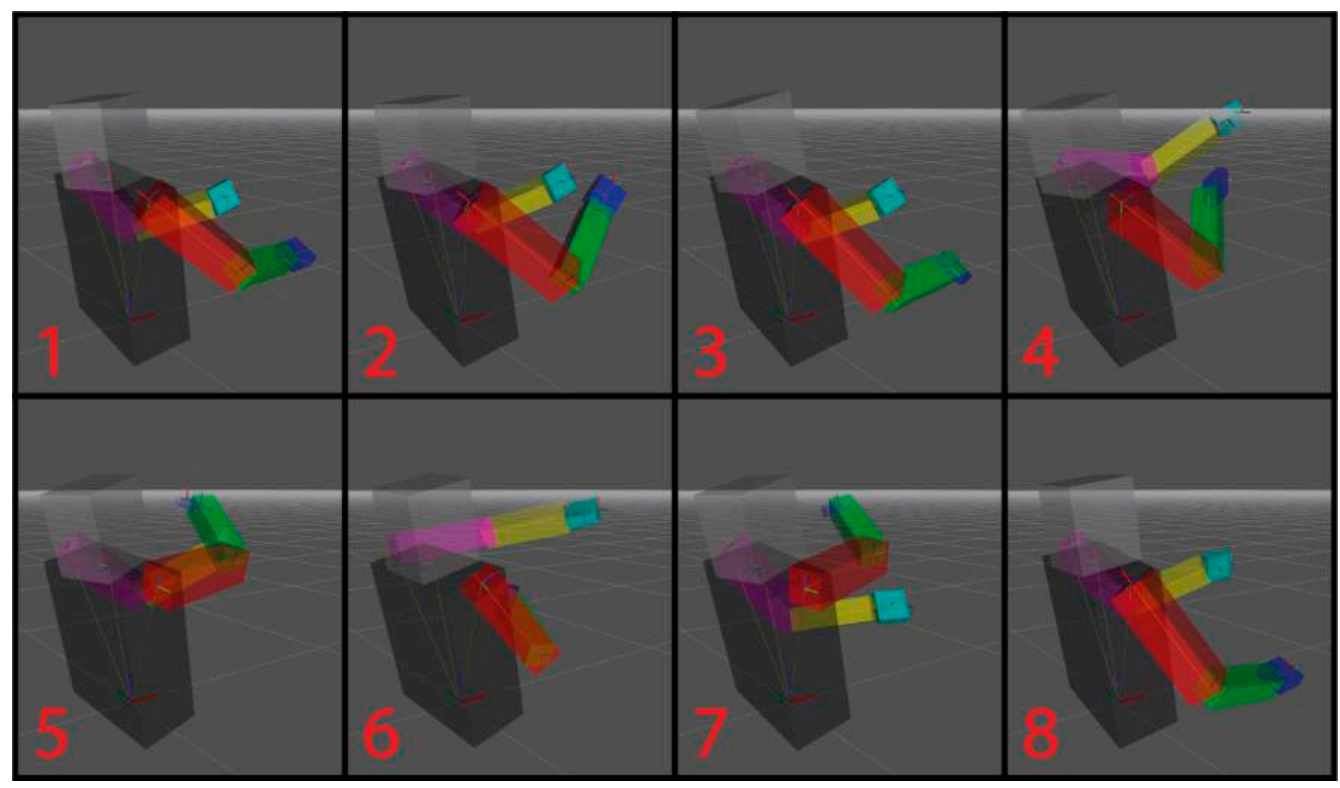

Figure 13. Three-dimensional driver model during the slalom scenario: 1 . gearing in 1st; 2 . both hands on the steering wheel; 3 . gearing into 2 nd; 4 . preparing the slalom entry; 5 . turning to the left (1st cone); 6. turning to the right (2nd and 3rd cones); 7. turning to the left (3rd and 4th cones) and 8. finishing manoeuvre.

Figure 13 shows a reconstruction of the 3D model of a driver who performed a lane change trajectory test (slalom) in which a vehicle with manual transmission was used. In the first action (1), the driver held the steering wheel with their left hand while their right hand placed the gearbox lever into first gear. Next, the driver placed both hands on the steering wheel (2), driving in a straight line to approach the area where the cones were circumvented. Next, the driver held the steering wheel with their left hand and, with the help of their right hand, engaged second gear (3). In the next position (4), the driver placed both hands on the steering wheel again, turning it to the left to perform the manoeuvre to circumvent the first cone, which is on the left side of the vehicle. In the following movement (5), the driver turned the steering wheel totally with both hands to the left to pass between the first and second cones. In the manoeuvre (6), the steering wheel turned to the right again with both hands, so that the vehicle circulated between the second and third cones. In the following manoeuvre (7), the vehicle circulated between the third and fourth cones when turning the steering wheel to the left. Finally, in the manoeuvre (8), movement is represented once the fourth cone has been circumvented and the driver left the fifth cone on their left side and arranged to place the gear lever into neutral position.

In this figure, a set of discrete positions of the 3D model, corresponding to the most unfavourable driver's upper extremity range of motion, is shown. Analysis of the results would allow for reproduction of continuous motion of the sequence followed. The results obtained in this 3D model were analysed in the 24 tests carried out, obtaining values that were very close to reality.

\section{Discussion}

The design of the DAS and its application in real experimental tests have provided valid and suitable results for the case studied. After having performed analysis of the data obtained, it can be concluded that the developed system meets the objectives and requirements established initially. The requirements on which the DAS was designed were based on the fact that it had to be reliable, robust and portable.

The system presents reliability, given that all sensors provide a range of values that exceed the minimum and maximum expected values in research testing as well as a resolution that shows enough 
quality in the data obtained. In addition, in the described methodology, calibration of each sensor is carried out prior to its use, so it can be ensured that all testing results have been obtained with minimized measurement error. Finally, the selected sensors belong to manufacturers with extensive experience in sensor development and production. As there are many manufacturers on the market whose sensors meet the technical specifications required to carry out these experiments, all sensors used in this system could be replaced by others belonging to different manufacturers. Before that, the user must review that the same data acquisition characteristics can be reproduced, with similar scale ranges and precision.

Regarding the quality of the results obtained, it can be affirmed that, qualitatively, the behaviour of the signals registered in all tests followed the same trend for the two tested vehicles and the three participating drivers (24 tests in total). Analysis of the driving signals stored in roundabouts and in lane change operations (slalom) showed a similar trend, without finding distortions of the data obtained for the measurement of forces, torques and inertial movements. The same statement can be made for braking tests, where, except for one case in which the DAS started recording prematurely, all tests showed similar behaviour.

From a quantitative point of view, the results showed that, in roundabouts and obstacle avoidance manoeuvres (slalom), the maximum values for steering wheel force obtained reached $24.2 \mathrm{~N}$. In the case of braking tests, the maximum values ranged between 85.6 and $137.5 \mathrm{~N}$, very close to the expected values according to previous investigations carried out by other research teams [11-14].

Regarding robustness of the proposed solution, after performing the physical tests on the track, no possible failure was detected that slowed down the activities to be carried out. The DAS used in the experiments showed that its implementation in the tested vehicles required a reasonable installation time (less than 90 minutes), including the sensor calibration process. Additionally, execution of the tests took place in a relatively short time. Each of the tests required less than 15 minutes to record data, including the adjustment time of the driver to the driving position, the execution of the test itself and the verification that all the data had been logged correctly. In addition to this amount of time, adding the time that corresponds to prior preparation of the driver for the motion tracker installation is required. It could be stated that the total run time of the required tests with each vehicle and driver did not exceed 150 minutes. The total time required can be considered as reasonable and acceptable for extending the same testing procedure to further drivers and vehicles in the future that will allow for generation of a proper database.

In relation to portability of the system, this was guaranteed through the selection of equipment that has been easily assembled into one vehicle, and after the test, it has been efficiently moved and installed into another vehicle, needing a reduced amount of time. Development of the experimental tests with different drivers in different vehicles demonstrated the portability of the DAS since the installation and removal from one vehicle to another did not produce any type of errors or failures.

Finally, it could be concluded that the DAS has proven to be robust and reliable enough for a more complex data collection on a greater number of vehicles of different types (category, transmission, weights, dimensions, steering assist, brake assistance, etc.) and drivers (with different ages, experience, sex and height).

The data collected with the DAS developed in this research would allow for definition of the thresholds of operative forces required to act on the steering wheel and the brake pedal. These thresholds would refer to vehicles on the market, based on real measurements obtained with these vehicles, by performing manoeuvres very similar to those carried out under normal circulation conditions.

One of the characteristics of the results obtained in this experience is the fact that the data come from vehicles in dynamic scenarios (and not measured in static conditions). By this way, the results obtained provide a better representation of real daily driving manoeuvres. This differentiates them from data that could be obtained from a measurement in a driving simulator, where the base can be static or dynamic, depending on its technology and capacity. It is required to take into account that, in driving simulators, vehicle assistance devices are usually replaced by electric motors (steering) or 
hydraulic devices (brakes) which simulate the behaviour of a real vehicle but which do not reproduce the same operating conditions of a real dynamic vehicle. These real conditions justify that the results obtained from the DAS developed can be used with greater confidence and reliability than those that could be obtained from a driving simulator. However, driving simulators could be used as an experimental tool in the fitness-to-drive assessment to measure the forces that the driver can exert on the periphery of the steering wheel and on the brake pedal [6]. If the appropriate scenarios [15] are reproduced to measure the driver's capabilities during simulation, the data could be contrasted with real data obtained from the database generated with the DAS developed in this work.

Furthermore, the obtained results can be used to define the reference values that will be compared with results measured in the fitness-to-drive assessments for driver's with disabilities carried out in specialized evaluation centres. Specifically, the measurement of the force applied on the steering wheel and on the brake pedal would be defined more precisely following codes 20.07 "Brake operation with maximum force of $\ldots \mathrm{N}$ " and 40.01 "Steering with maximum operation force of ... N", which establishes EU directive 2015/653 [5]. The reference values obtained from the DAS developed will facilitate, in the future, a better evaluation of the driving ability of drivers with disabilities, and it will finally determine the need, or not, to modify the primary controls of the given motor vehicle to their specific requirements.

On the other hand, taking into account the results obtained from the movement of the driver's trunk and upper extremities during the manoeuvres carried out in this experiment, analysis of the ergonomic data recorded in all the tests has allowed for establishment of the maximum ranges of movement that are carried out in the most common driving manoeuvres. This data is essential so that experts in the evaluation of drivers with disabilities [6] can determine the types of technical aids that a driver with any type of physical disability will need to adapt a motor vehicle. Determination of the mobility ranges of a driver in a previous fitness-to-drive evaluation can be compared with the data obtained with the help of the DAS developed in this work.

To conclude, all data obtained with the aim of the DAS developed will contribute to substantially improving the fitness-to-drive assessment for drivers in general and for disabled people in particular when obtaining or renewing their driving license.

Although the objectives of this project have been met, the inclusion of a load cell in the clutch pedal is proposed as a future development. By this improvement, a more detailed measurement of the forces required during the gear change procedure can be obtained that will give more information relevant for driving manual transmission vehicles. Moreover, it is advisable to use a wireless connection between the load cell sensor and the Arduino UNO board located at the steering wheel in order to improve comfort and drivability when doing the test, avoiding wires and cables that could cause difficult drivability of the vehicle. Lastly, an automatic procedure to convert, filter and analyse the data must be developed.

Author Contributions: The contribution of authors to develop the research and written the article was the following: conceptualization, J.F.D.; methodology, J.F.D. and V.G.-J.; software, V.G.-J. and Á.L.; validation, V.G.-J., Á.L. and J.C.; formal analysis, V.G.-J., Á.L. and J.C.; resources, J.F.D.; data curation, V.G.-J., Á.L. and J.C.; writing—original draft preparation, J.F.D. and Á.L.; writing—review and editing, J.F.D., V.G.-J., Á.L. and J.C.; supervision, J.F.D.; project administration, J.F.D.; funding acquisition, J.F.D. All authors have read and agreed to the published version of the manuscript.

Funding: This research was funded by Generalitat Valenciana (Spain) under grant APOSTD/2017/055 and by the Universitat Politècnica de València (UPV) (Spain) under the project Characterization of biomechanical and ergonomic thresholds in driving motor vehicles applicable to driver evaluation (Ref. 20190480). This research has been approved by the UPV Ethical Committee at a session celebrated on 18 June 2019 (ref. P5_18_06_19).

Acknowledgments: The authors of this article express their acknowledgement to the drivers participating in the experimental tests and to the technical support of the Technical Service of Vehicle Reforms of Valencia (SETRAV) who provided the data from the vehicles involved in the research.

Conflicts of Interest: The authors declare no conflict of interest. The funders had no role in the design of the study; in the collection, analyses or interpretation of data; in the writing of the manuscript; or in the decision to publish the results. 


\section{References}

1. WHO. World Disability Report; World Health Organization: Geneva, Switzerland, 2011; ISBN 978-92-4-068823-0.

2. Disability Statistics. Available online: https://ec.europa.eu/eurostat/statistics-explained/index.php?title= Disability_statistics_introduced (accessed on 29 March 2019).

3. European Commission. Flash Eurobarometer 345; Accessibility; Report; Directorate-General Justice and Coordinated by Directorate-General for Communication; Brussels. 2012. Available online: https://ec.europa. eu/commfrontoffice/publicopinion/flash/fl_345_en.pdf (accessed on 15 March 2020).

4. European Commission. Directive (EU) 2006/126/EC of the European Parliament and of the Council of 20 December 2006 on Driving Licenses; OJEU L403/18; European Commission: Brussels, Belgium, 2006.

5. European Commission. Directive (EU) 2015/653 of 24 April 2015 Amending Directive 2006/126/EC of the European Parliament and of the Council on Driving Licenses; European Commission: Brussels, Belgium, 2015.

6. Dols, J.; Valdés, E. Marco legal en el proceso de obtención del permiso de conducción por parte de conductores con movilidad reducida y su puesta en práctica. In Manual Descriptivo del Protocolo de Evaluación de Conductores con Discapacidad Motora Utilizado en España Ed; Dir. General de Tráfico, 2 ed.; DGT: Madrid, Spain, 2017; pp. $45-85$.

7. Luna, A. Diseño e Implementación de un Sistema de Adquisición de Datos Para la Caracterización de los Esfuerzos y Movimientos del Conductor en la Conducción de Vehículos Automóviles. Ph.D. Thesis, Graduate Dissertation Universitat Politècnica de València. Universitat Politècnica de València, Valencia, Spain, 2018. Available online: https://riunet.upv.es/handle/10251/114785 (accessed on 20 May 2019).

8. ENAC. Criterios Generales para la Acreditación de Laboratorios de Ensayo y Calibración Según Norma UNE-EN ISO/IEC 17025:2017; Entidad Nacional de Acreditación (ENAC): Madrid, Spain, 2018; Available online: https://www.enac.es/documents/7020/b7e24234-daba-4a62-9652-76eb7e96db30 (accessed on 13 March 2019).

9. Solier, J. Calibración y Validación Experimental de los Sistemas de Dirección, Frenado y Acelerador del Simulador de Autobús Safebus. Ph.D. Thesis, Graduate Disertation Universitat Politècnica de València. Universitat Politècnica de València, Valencia, Spain, 2017. Available online: http://hdl.handle.net/10251/88173 (accessed on 16 May 2019).

10. Girbés, V.; Hernández, D.; Armesto, L.; Dols, J.F.; Sala, A. Drive Force and Longitudinal Dynamics Estimation in Heavy-Duty Vehicles. Sensors 2019, 19, 3515. [CrossRef] [PubMed]

11. Dols, J.; Mirabet, E. Análisis experimental de los rangos de movilidad articular y fuerza muscular requerida para la conducción de vehículos automóviles. Securitas Vialis 2008, 1, 17-26. [CrossRef]

12. Pettigrew, K. Assessment of the physical abilities of disabled drivers. New South Wales. In Proceedings of the 18th Annual Conference of the Ergonomics Society of Australia and New Zealand Inc. Canberra, 1981; Ergonomics Society of Australia and New Zealand, Sidney, Australia, 26-27 November 1981; pp. 73-91.

13. Kember, P. Strength Abilities of Disabled Drivers and Control Characteristics of Cars; TRRL.CR125; Transport and Road Research Laboratory: Crowtorne, UK, 1991.

14. Horberry, T.; Inwood, C. Defining criteria for the functional assessment of driving. Appl. Ergon. 2010, 41, 796-805. [CrossRef] [PubMed]

15. Dols, J.; Molina, J.; Camacho-Torregrosa, F.J.; Marín-Morales, F.J.; Pérez-Zuriaga, A.; García, A. Design and Development of Driving simulator scenarios for road validation studies. Transp. Res. Procedia 2016, 18, 289-296. [CrossRef]

(C) 2020 by the authors. Licensee MDPI, Basel, Switzerland. This article is an open access article distributed under the terms and conditions of the Creative Commons Attribution (CC BY) license (http://creativecommons.org/licenses/by/4.0/). 